\title{
A CENA PEDAGÓGICA DO CULTIVO DO JARDIM NO EMÍLIO DE ROUSSEAU
}

\author{
THE PEDAGOGICAL SCENE OF THE PLANTING A GARDEN IN EMILE OF \\ ROUSSEAU
}
LA ESCENA PEDAGÓGICA DEL CULTIVO DEL JARDÍN EN EL EMILIO, DE ROUS- SEAU

\author{
Maria de Fátima Simões Francisco \\ Professora de Filosofia da Educação da FEUSP. \\ simoes@usp.br
}

\begin{abstract}
RESUMO: Trata-se de analisar a passagem do livro II do Emílio ou da educação de Rousseau, em que o aluno imaginário, nesse momento na segunda etapa da infância, vai ter sua primeira aprendizagem moral, em torno da noção de propriedade privada. A aquisição se dá através da experiência de cultivo de favas num jardim. Nosso propósito é interrogar acerca de que concepção particular de propriedade privada da terra o autor ensinará a Emílio. Apesar de, à primeira vista, parece que ele se preocupa apenas em legitimar essa instituição, ao apresentar seu fundamento - o direito do primeiro ocupante da terra pelo trabalho e cultivo - observamos que a lição se aprofundará à medida que avança e se tornará bastante crítica. Dessa forma, encontraríamos uma consistência entre essa apresentação da propriedade ao aluno encontrada no Emílio e o tratamento bastante crítico dado à instituição no Discurso sobre a origem e os fundamentos da desigualdade entre os homens, no qual é a origem do maior mal das sociedades vigentes, a desigualdade.
\end{abstract}

PALAVRAS-CHAVE: Propriedade. Trabalho. Educação.

ABSTRACT: We intend to analyse a part in Emile, or On Education, book II where the imaginary eleven, who is in the second phasis of childhood at that moment, is going to have his first moral learning about the notion of private property. The learning occurs by the experience of planting a garden. We want to ask about which particular conception of property the author is going to teach. Although it looks like at the first sight he seems to worry only in showing the legitimacy of this institution by presenting its basis, the right of the first occupant by labor, we note that the lesson will get deeper and very critical. So we will find a harmony between this presentation of property to the student found in his work Emile and the very critical treatment given to it in his work Discourse on the origin and the foundations of the inequality among men, where it is the origin of the worst problem in the present society, the inequality.

KEYWORDS: Property. Labor. Education.

RESUMEN: Es un trabajo de análisis de una paisaje del libro II del Emilio o de la educación de Rousseau, en el que el alumno imaginario, en ese momento en la segunda período de la niñez, tendrá su primer aprendizaje moral, en torno de la noción de propiedad privada. La adquisición se realiza a través de la experiencia del cultivo de habas en el jardín. Nuestro propósito es interrogar a respecto de qué concepción particular de la propiedad privada de la tierra el autor enseñará el autor a Emilio. Aunque, de inmediato, pueda parecer que él se preocupa solamente en esa institución, al presentar su fundamento - el derecho del primer ocupante de la tierra por el trabajo y el cultivo observamos que la lección se profundiza mientras que avanza e tornase muy crítica. De esta manera, encontraríamos una consistencia entre esa presentación de la prosperidad en el alumno encontrado no Emilio y el tratamiento demasiado crítico que es dado a la institución en el Discurso sobre el origen y los fundamentos de la desigualdad entre los hombres, en que la origen del mayor mal de las sociedades que están vigentes, la desigualdad.

PALABRAS CLAVE: Propiedad. Trabajo. Educación.

Artigo recebido em setembro de 2015

Aprovado em novembro de 2015

Cad. Pes., São Luís, v. 22, n. Especial, set./dez. 2015 
No livro II de Emílio ou da educação, Rousseau nos alerta que o primeiro e mais urgente ensinamento moral a ser dada a Emílio criança diz respeito à noção de propriedade privada da terra. Isso justamente depois de tê-lo acompanhado afirmar com veemência na abertura da segunda parte do Discurso sobre a origem e os fundamentos da desigualdade entre os homens que o advento dessa instituição foi um decisivo fator negativo na história dos povos humanos e fonte maior de todos os males, por ser a responsável pela introdução da desigualdade entre os homens. ${ }^{1}$ Como se pode entender mais esse aparente paradoxo deste que já fora dito filósofo dos paradoxos? De posse da visão, que ganhou a adesão de muitos, particularmente na área de ciência política, de um Rousseau liberal, defensor, ao lado de Locke, dos valores da sociedade burguesa - o que poderia lhe cair bem uma vez que foi leitura fundamental dos revolucionários de 1789 - poderíamos interpretar a lição sobre a propriedade no Emílio como visando à transmissão de uma concepção positiva e apologética daquela instituição. Ademais que a própria lição traria alguns elementos que fomentariam essa leitura. Quando adotamos essa interpretação, nos deparamos, entretanto, com um problema. Se acreditarmos haver no pensamento de Rousseau uma estrita unidade, como acomodar essa interpretação da lição sobre a propriedade do Emílio com a profunda crítica que encontramos a essa instituição no Segundo Discurso? Como crer ser simplesmente esse o sentido dessa lição quando o vemos, por exemplo, afirmar, na reconstituição da história dos povos humanos, que a origem dos males do mais desafortunado período da história humana, o do homem civilizado, coincide e se relaciona diretamente com advento da apropriação privada, exclusiva e excludente, da terra? E ainda: como tomar a lição como apologia e legitimação da propriedade privada, quando o vemos avaliar o estágio de homem selvagem em que aquela instituição ainda não existe, mas a propriedade coletiva da terra - foi o mais feliz da humanidade e aquele em que a história humana deveria ter parado?

A tomarmos a sério a crítica contundente à propriedade privada do Segundo Discurso, precisaremos fazer outra interpretação da lição moral sobre a propriedade do Emílio, a fim de fazê-la se harmonizar com aquela crítica. Na verdade, é notável que, ao analisar com cuidado as páginas da lição, encontramos no autor uma preocupação que vai muito além da legitimação da instituição da propriedade. Afastada a aparente contradição, constatamos que, consoante à investida contra a propriedade no Segundo Discurso, Rousseau propõe no Emílio a seu aluno, uma lição bastante crítica acerca daquela instituição e de seu efeito prejudicial maior que é a introdução da desigualdade entre os homens.

Entretanto, não é apenas o conteúdo da primeira lição moral que chama a atenção no episódio das favas. A própria forma pela qual a lição transcorre nos reserva múltiplas surpresas. Acompanhemos os passos da lição, a fim de captar essas duas dimensões.

Logo ao início do episódio deparamos com uma advertência: "meu objetivo não é entrar em todos os pormenores, mas apenas expor as máximas gerais e dar exemplos para as ocasiões difíceis" (ROUSSEAU, 1995, p. 97). Se no Emílio o que se pretende na maior parte do tempo é meramente fornecer os princípios gerais da educação do homem, sem dar exemplos de como eles devem ser aplicados na prática pelo educador, procedimento diverso se tomará nas ocasiões difíceis. ${ }^{2}$ Avaliando a lição sobre a propriedade como uma dessas ocasiões, em que é necessária

\footnotetext{
1 O verdadeiro fundador da sociedade civil foi o primeiro que, tendo cercado um terreno, lembrou-se de dizer isto é meu e encontrou pessoas suficientemente simples para acreditá-lo. Quantos crimes, guerras, assassinatos, misérias e horrores não pouparia ao gênero humano aquele que, arrancando as estacas ou enchendo o fosso, tivesse gritado a seus semelhantes: Defendei-vos de ouvir esse impostor; estareis perdidos se esquecerdes que os frutos são de todos e a terra não pertence a ninguém!” (ROUSSEAU, 1973, p. 265).

2 Sobre os propósitos do autor nos momentos da obra em que o personagem Emílio aparece encenando numa
} 
a ilustração do princípio pedagógico num exemplo concreto, o filósofo propõe uma história em que o aluno Emílio e seu preceptor entram em cena ${ }^{3}$ para mostrar como a lição precisaria ser conduzida.

Por que se trata de uma ocasião difícil o da aprendizagem da noção moral de propriedade privada? Sendo o primeiro passo de uma instrução moral, a criança será introduzida no universo da relação com o semelhante. O propósito será o de dar à criança "alguma idéia das relações de homem para homem e da moralidade das ações humanas" (ROUSSEAU, 1995, p. 97). De outra parte, sabemos pelo Segundo Discurso, que os problemas do homem têm início quando deixa a vida solitária do estado de natureza e passa a estabelecer relação contínua e de dependência com o semelhante e compor uma sociedade. A maior parte das desventuras da história do homem se deve ao desdobramento das implicações envolvidas no processo de socialização entre homens naturais. Sabemos ainda que o pensamento do autor se desenrola em torno de um núcleo central maior que é a oposição entre natureza e sociedade. Dialogando estreitamente com as idéias do Segundo Discurso e com a história ali exposta dos povos ${ }^{4}$, o momento do primeiro contato da criança com o outro assumirá importância decisiva, demandando então atenção cuidadosa por parte do preceptor. Vale dizer, a primeira lição moral precisará ser bem conduzida pelo preceptor e bem assimilada pelo aluno. A preocupação de Rousseau com a boa aprendizagem das relações homem-homem ou da moralidade das ações visaria permitir a Emílio uma história futura de relações com o semelhante diversa daquela observada no estado presente entre os homens.

pequena narrativa, vide as páginas 27-28 do livro I. Ali Rousseau nos apresenta o aluno imaginário e explica as funções das cenas protagonizadas por ele, dentre as quais a de mostrar a verdade e a aplicação das máximas de educação que podem apresentar maior dificuldade de compreensão: "eis o que procurei fazer em todas as dificuldades que se apresentaram. Para não engrossar inutilmente o livro, contentei-me em colocar os princípios, cuja verdade cada qual deve perceber. Mas, quanto às regras que podiam precisar de provas, apliquei-as todas ao meu Emílio ou a outros exemplos, e mostrei em pormenores bastante extensos como podia ser realizado o que eu estabelecia" (ROUSSEAU, 1995, p. 28).

${ }^{3}$ A ideia do aluno Emílio e seu preceptor, o próprio Rousseau, entrarem em cena volta e meia no tratado filosófico de educação, que é na maior parte do tempo o texto do Emílio, representando papéis e atuando ao longo de uma breve narrativa é algo referido pelo próprio autor, vide, por exemplo, a p. 28, do livro I (ROUSSEAU, 1995). Quando empregamos o termo "cena pedagógica" para designar esses episódios, estamos seguindo Fortes que chama a atenção para a presença constante da imagem do teatro no Emílio, sob diferentes formas, dentre as quais as "pequenas cenas pedagógicas" em que atuam o aluno e seu preceptor: "a educação será toda ministrada pelo meio de uma sucessão regulada de cenas que poderíamos perfeitamente enumerar." Nos dois primeiros atos - isto é, os livros II e III - contamos doze cenas" (FORTES, 1979, p. 82). Fortes vai também chamar a atenção para a existência nessas cenas de uma "ação de natureza quase dramática", com a finalidade de "ultrapassar a retórica das educações habituais" (FORTES, 1979, p. 82), visando aqui o tratado de educação de Locke. "Não devemos esquecer o alcance crítico de toda esta pedagogia." Rousseau visa o tempo todo ultrapassar uma concepção da pedagogia ou do conhecimento puramente "especulativa", puramente contemplativa ou retórica" (FORTES, 1979, p. 83).

${ }^{4}$ Recordemos que Rousseau propõe mais de uma vez no Emílio o paralelismo entre essa obra e o Segundo Discurso, e entre a história de vida do homem individual desde o nascimento e a história dos povos humanos. Vargas aponta para esse paralelismo ao falar da criança do livro II: "a criança dessa idade é muito semelhante ao selvagem sem memória e sem previdência, de que fala o Discurso sobre a origem da desigualdade. É um mundo fechado em si mesmo, coeso" (VARGAS, 1995, p. 46).

${ }^{5}$ De acordo com As Confissões, o Emílio seria um tratado que demonstra a bondade natural do homem. Rousseau pretenderia nele apresentar, no plano da história de vida do indivíduo humano, trajetória inversa àquela da história dos povos humanos. Ou seja, enquanto nesta última o estado presente do homem implicou a perda das vantajosas disposições naturais e a negação do homem da natureza, inversamente, no Emílio, a intenção seria demonstrar como possível o nascimento do homem civil a partir do homem natural, a natureza podendo dar origem à sociedade sem anular a si mesma, enfim, natureza e sociedade podendo ser conciliáveis. 
Além disso, se Rousseau pretende no Emílio propor, no plano teórico, o projeto de formação de um outro homem e, por meio deste uma outra sociedade - outros que o homem e a sociedades existentes no presente, no plano dos fatos -, o momento de educar para a relação com o outro reveste importância singular. Pois a construção de novas formas de relações sociais depende das relações morais que se ensinam às crianças. Notemos então que a instrução moral que se inicia com a propriedade não visa somente a formação da conduta moral. De modo mais amplo, visa à própria conduta social e política do indivíduo. Por isso, não deveríamos tomar de modo simplista o início do livro I: que se opta ali por formar o homem, não o cidadão, e que se tem em vista a educação da natureza ou doméstica e não a educação pública. Por trás da intenção de ensinar ao indivíduo Emílio as relações homem-homem e a moralidade das ações, está o propósito de formar também o homem civil Emílio, futuro membro da sociedade política; a educação moral de Emílio seria assim parte de uma educação civil ou política. Desse modo, por trás da primeira lição moral se tem em vista não apenas a identidade moral do futuro membro da família, mas de modo mais amplo a identidade civil do futuro membro do corpo político.

Mas a ilustração da lição numa situação concreta será necessária, sobretudo, porque, tratando-se a noção a ensinar a de propriedade privada, está colocada uma área de conflito entre os homens. Eis aí a razão principal de estarmos diante de uma "ocasião difícil". A primeira e mais urgente noção moral a ser ensinada à criança, nos é dito, será a de propriedade para que "ela não se julgue senhora de tudo e não faça mal aos outros, sem escrúpulos e sem o saber" (ROUSSEAU, 1995, p. 97). A lição abordará o meu e o do outro, o de que cada um se acredita senhor exclusivo, excluindo todos os outros do seu usufruto. Ora, sabemos que na psicologia rousseauísta o homem é movido por duas paixões, dadas por natureza, o amor de si e a piedade natural. A primeira o leva a buscar continuamente seu bem-estar; movida por ela a criança lançará mão e julgará ter direito a tudo o de que, ao seu redor, necessite. A segunda paixão, por torná-lo sensível ao sofrimento alheio, leva-o a sair de si, colocar-se no lugar do outro e, por consequência, evitar causar-Ihe mal; constitui, assim, um freio quando do exercício exacerbado da primeira paixão. ${ }^{6} \mathrm{O}$ conflito de interesses, que nasce do amor de si, e é eventualidade presente, mas atenuada, no estágio pré-propriedade privada, torna-se, uma vez aquela fundada, realidade a opor continua e radicalmente os homens. ${ }^{7}$ De modo significativo, no Segundo Discurso, quando surge no segundo estado o primeiro germe de propriedade privada, os terrenos ocupados pelas cabanas, emergem

\footnotetext{
${ }^{6}$ Essas duas paixões são conceitos complexos em Rousseau, guardando múltiplos aspectos. Não é nossa intenção nem podemos nos limites desse artigo aprofundar a questão dessas duas paixões naturais. Escolhemos uma passagem central, em que são resumidamente apresentadas pelo autor no prefácio do Segundo Discurso: "deixando de lado, pois, todos os livros científicos, que só nos ensinam a ver os homens como eles se fizeram, e meditando sobre as primeiras e mais simples operações da alma humana, creio nela perceber dois princípios anteriores á razão, um dos quais interessa profundamente ao nosso bem-estar e à nossa conservação, e o outro nos inspira uma repugnância natural por ver perecer ou sofrer qualquer ser sensível e principalmente nossos semelhantes" (ROUSSEAU, 1973, p. 236). Encontramos na primeira parte dessa obra, quando trata do homem natural do ponto de vista moral, páginas 258-261, um longo tratamento da paixão da piedade.

${ }^{7}$ No estágio em que a propriedade se instaura e se espalha cobrindo toda a Terra, Rousseau aponta que não se trata mais aí da atuação da paixão natural do amor de si. E, sim, de uma paixão distinta, que marca as relações entre os homens na sociedade do estado presente, o amor próprio. Sobre ela, o autor apresenta a significativa nota "o", no Segundo Discurso: "não se deve confundir o amor próprio com o amor de si mesmo; são duas paixões bastante diferentes [...] O amor de si mesmo é um sentimento natural que leva todo animal a velar pela própria conservação e que, no homem dirigido pela razão e modificado pela piedade, produz a humanidade e a virtude. O amor próprio não passa de um sentimento relativo, fictício e nascido na sociedade, que leva cada indivíduo a fazer mais caso de si do que de qualquer outro, que inspira aos homens todos os males que se causam e que constitui a verdadeira fonte da honra" (ROUSSEAU, 1973, p. 313).
} 
também os primeiros conflitos e a primeira oposição de interesses. ${ }^{8}$ No terceiro estado, a instalação plena da propriedade, e seu principal efeito, a desigualdade, conduzem os homens ao ponto máximo da oposição de interesses e ao estado de guerra. ${ }^{9}$ Essa dimensão da propriedade, de amplificar o conflito e antagonismo entre os interesses precisará também ser ensinada a Emílio na lição.

De acordo com o Emílio, a paixão que move o homem desde seu nascimento, que governa a criança e impera por toda a infância é o amor de si. A segunda paixão natural, a piedade, por sua vez, não se desenvolve logo de início na vida do homem, na infância, nem pode se desenvolver espontaneamente, dependendo da intervenção do mestre homem e da tarefa da educação para ser adquirida. É para o fato de a criança ser naturalmente concentrada em si e movida unicamente pelo amor de si, ou, por assim dizer, para o "narcisismo"10 como o traço maior das ações na infância, que o texto da lição chama atenção logo de início:

\begin{abstract}
"nossos primeiros deveres são para com nós mesmos; nossos sentimentos primitivos concentram-se em nós mesmos; todos os nossos movimentos naturais relacionam-se primeiramente com nossa conservação e nosso bem estar. Assim, o primeiro sentimento de justiça não nos vem daquela que nós devemos, mas sim da que nos é devida." (ROUSSEAU, 1995, p. 97).
\end{abstract}

A primeira lição moral, sobre o dever em relação ao outro e a justiça que devemos a ele, será ministrada para um ser que se encontra num mundo inteiramente diferente do mundo moral. A criança só conhece e se move pelo desejo do próprio bem-estar, e, portanto, num certo sentido, só é capaz de conceber os direitos que tem e os deveres ou a justiça que devem a ela. Trata-se o mundo infantil de um mundo concentrado e voltado para si mesmo; habitado por uma só pessoa, a própria criança, que por sua vez está rodeada por coisas, dentre as quais se tem, de um lado, os homens-coisa e, de outro, as coisas-coisa. ${ }^{11}$ Como ensinar a esse ser assim constituído o dever em relação ao outro e a justiça que deve a ele? Tendo já em desdobramento o amor de si, será preciso, a partir de certa idade e em função das necessidades introduzidas pelas relações com os outros, adquirir também a paixão da piedade. Não podendo o mestre-natureza desdobrar sozinho essa tarefa, precisará, como dissemos, contar com o mestre-homem.

No decorrer da primeira lição moral observamos o movimento da educação, a progressão da

\footnotetext{
8 "Logo, deixando de adormecer sob a primeira árvore, ou de se refugiar nas cavernas, encontrou alguns tipos de machados de pedras duras e cortantes que serviram para cortar madeira, cavar a terra e construir cabanas de galhos [...] Essa foi a época de uma primeira revolução, que fixou e distinguiu as famílias, e que introduziu uma espécie de propriedade, da qual nasceram muitas querelas e combates" (ROUSSEAU, 1973, p. 88).

9 "Em uma palavra, há, de um lado, concorrência e rivalidade, de outro, oposição de interesses e, de ambos, o bdesejo oculto de alcançar lucros a expensas de outrem. Todos esses males constituem o primeiro efeito da propriedade e o cortejo inseparável da desigualdade nascente" (ROUSSEAU, 1973, p. 273). Para a descrição completa do surgimento da propriedade privada no terceiro estado e suas implicações, vide as páginas 271-275 do Segundo Discurso.

${ }^{10}$ Usamos o termo seguindo a leitura proposta por Fortes. O autor interpreta o episódio da propriedade e a tarefa da educação como um todo, além da aquisição de conhecimento, como um movimento de ultrapassamento do narcisismo: "trata-se de exprimir, com efeito, este movimento de ultrapassamento do "narcisismo" que se acha na base do verdadeiro conhecimento" (FORTES, 1979, p. 83). Fortes (1979) tem em vista, de um lado, a crítica de Rousseau no primeiro discurso aos sentidos assumidos pelo conhecimento para os que o produzem e, de outro, o importante prefácio da peça Narciso ou o amante de si em que o narcisismo é apresentado como marca saliente da sociedade presente.

${ }^{11}$ É o que diz Vargas: "trata-se de um mundo sem intersubjetividade, sem dimensão moral" (VARGAS, 1995, p. 48).
} 
criança de pessoa concentrada em si e fechada em seu mundo habitado apenas por si, para pessoa, em certa medida, capaz de sair de si, se colocar no lugar de um outro e, desse modo, encontrá-lo. Ou seja, a ampliação desse mundo habitado por uma só "pessoa" pela introdução de outras "pessoas. Essa progressão da criança será visada, notemos, tratando-se de ensinar a propriedade, isto é, uma noção que embute em si um potencial de conflito. Como a intenção com essa instrução moral é dar o primeiro passo para se construir outra forma de relação social, diferente da vigente nas sociedades existentes, a lição sobre a propriedade privada não pode se limitar a fazer a apologia e a legitimação dessa instituição.

Logo de início percebemos que em termos de método a lição consistirá não em palavras - a exposição pelo mestre do conteúdo organizado e pronto para ser assimilado, mas em ações - na vivência prática do ter uma propriedade. Poderíamos, diz Rousseau, pensar em ensinar à criança o que é possuir algo apontando os objetos de que é dona, seus trapos, brinquedos e móveis. Mas essa forma de propriedade estando já instituída, a criança não vai aprender como se forma a propriedade. Se lhe dissermos, por outro lado, que aquelas coisas foram dadas a ela, ao invés de se simplificar, a lição se complica, pois além de permanecer a dificuldade de explicar a origem da propriedade ali estabelecida, acresce-se a dificuldade de explicar o que vem a ser a convenção do dom. A única saída, segue o texto, será, em lugar de explicar a propriedade já instituída, ensinar numa situação prática, de que a criança será a protagonista, o processo de surgimento de uma propriedade. Em lugar de ouvinte passivo da preleção do mestre da pedagogia tradicional, a criança se fará ator numa situação prática, propõe a pedagogia do autor. Conforme Fortes (1979), teremos uma verdadeira peça teatral - com protagonista, coadjuvante, enredo, conflito dramático, desenlace - a serviço da educação e da aquisição de conhecimento.

A noção a ensinar será a da origem da propriedade. Trata-se da noção de propriedade da terra como direito do primeiro ocupante pelo trabalho; aqui o autor retoma a concepção apresentada no Segundo Discurso. ${ }^{14}$ Emílio, vivendo no campo e vendo por toda parte plantações e homens cultivando a terra, terá o ímpeto de cultivar; a escolha da atividade se relaciona ao universo cultural do aprendiz. Com a ajuda do preceptor, o menino semeia favas num pequeno pedaço de terra, cuida delas diariamente, vê-las crescer e retira grande prazer disso. Com esse trabalho vemo-lo sentir-se senhor ao mesmo tempo da planta e da terra. ${ }^{15} \mathrm{O}$ preceptor, ator coadjuvante na cena, introduz nesse instante o conceito de "pertencer". A planta, diz ele, lhe pertence, pois pôs nela seu

\footnotetext{
12 "Jovens mestres, peço-vos que penseis nesse exemplo e vos lembreis de que em todas as coisas vossas lições devem consistir mais em atos do que em palavras, pois as crianças facilmente se esquecem do que disseram e do que lhes dissemos, mas não do que fizeram e do que lhes fizemos" (ROUSSEAU, 1995, p. 101).

13 "É o princípio de propriedade que lhe queremos explicar [...] trata-se, pois, de voltar à origem da propriedade, pois é de lá que a primeira idéia deve nascer" (ROUSSEAU, 1995, p. 98). "Nesse ensaio de fazer inculcar nas crianças as noções primitivas, vemos como a ideia de propriedade remonta naturalmente ao direito do primeiro ocupante pelo trabalho" (ROUSSEAU, p. 101).

14 "Da cultura de terras resultou necessariamente a sua partilha e, da propriedade, uma vez reconhecida, as primeiras regras de justiça [...] Essa origem mostra-se ainda mais natural, por ser impossível conceber a idéia de propriedade nascendo de algo que não a de mão de obra [...] Somente o trabalho, dando ao cultivador um direito sobre o produto da terra que ele trabalhou, dá-lhe consequentemente direito sobre a gleba pelo menos até a colheita, assim sendo cada ano; por determinar tal fato uma posse contínua, transforma-se facilmente em propriedade" (ROUSSEAU, 1973, p. 272). Rousseau parte aqui da concepção de Locke. Notar ainda que à propriedade segue-se a instituição de regras de justiça. De modo similar, no Emílio a noção de propriedade é um conteúdo do campo da moralidade e das relações homem-homem.

15 "Com certeza essa tomada de posse é mais sagrada e mais respeitável do que a de Nunes Balboa sobre a América meridional em nome do rei de Espanha, plantando seu estandarte nas costas do mar do Sul” (ROUSSEAU, 1995, p. 99).
} 
tempo, seu trabalho, seu sofrimento, sua pessoa. Tal qual the pertence seu braço. A explicação, diz o texto, aumenta ainda mais o prazer da criança. A planta é sua obra, sua criação, e assim uma parte de si, de forma análoga a uma parte de seu corpo. ${ }^{16}$ Nessa primeira parte, o episódio parece dar sequência e mesmo acentuar o movimento natural da criança de concentrar-se em si, buscar seu bem-estar e interesse, dar-se direitos. A atividade do cultivo da fava - que é dito "o seu bem" - e o prazer que sente com ela parece reforçar o amor de si que naturalmente a dirige. Podia-se dizer que ela vive um idílio amoroso consigo mesma, ${ }^{17}$ tal como o personagem Narciso ao descobrir sua face refletida ao cimo da água. Se a lição parasse por aqui diríamos que, ao invés de despertar a piedade natural e introduzir a criança no mundo das relações homem-homem e da moralidade das ações, o que ocorreu foi o reforço do amor de si e do "narcisismo" da criança. ${ }^{18}$ Mas, não nos inquietemos, ainda falta a segunda parte da lição.

"Mas eis que estávamos muito enganados" (ROUSSEAU, 1995, p. 100). Com essas palavras e boa reviravolta no enredo, entra em cena a figura do outro. Certo dia Emílio vem regar as favas e depara com todas arrancadas. Lágrimas, gemidos, gritos e, ainda, revolta e sentimento de injustiça. Fica-se sabendo que Robert, o jardineiro, fora o responsável pela devastação, ele é chamado. Ao ouvir as queixas do menino, ele não se cala nem se redime, ao contrário queixa-se mais alto. E, de modo surpreendente, ele está certo de se queixar mais alto, pois é o dono daquele terreno e acabara de sofrer dano e injustiça. Tendo semeado em sua propriedade preciosos melões de Malta, encontrara-os arruinados pela plantação de meras favas feita sobre eles. Também ele pusera na terra seu tempo, sua pena, seu trabalho e sua pessoa. $E$ também ele deparara com todo o seu trabalho arruinado. Vemos a seguir que Emílio detém o choro e as queixas e um pedido de desculpas ao jardineiro vem pela boca do preceptor. Tendo a criança acabado ela própria de viver a dor do trabalho destruído, adquiria a capacidade de se colocar no lugar do jardineiro e ser sensível à dor que ele sentira ao se deparar com a mesma cena de todo o esforço destruído. Vemos desenrolar-se no menino o movimento da piedade natura de colocar-se no lugar do outro, se identificar com ele e sentir sua dor. A descoberta da existência do outro ocorre, notemos, pela experiência da dor, e num certo sentido da violência, que esse outro Ihe traz. ${ }^{19}$ Isso

\footnotetext{
16 "Vimos todos os dias regar as favas, vemo-las germinar entre arroubos de alegria. Aumento ainda mais essa alegria dizendo-Ihe: isto lhe pertence. E, explicando-Ihe então a palavra pertencer, faço-a perceber que colocou ali seu tempo, seu trabalho, seu sofrimento, sua pessoa, enfim; que naquela terra existe algo que é dela mesma, que ela pode exigir contra quem quer que seja, da mesma forma como poderia retirar seu braço da mão de um outro homem que quisesse retê-la contra a sua vontade" (ROUSSEAU, 1995, p. 99).

${ }^{17}$ Quando a seguir dá com as favas arrancadas pensa: "Ah! Que aconteceu com meu trabalho, com a minha obra, o doce fruto de meus zelos e de meus suores? Quem me tirou meu bem?" (ROUSSEAU, 1995, p. 99). Fizemos uma alteração da tradução de Roberto Leal Ferreira, da edição Martins Fontes, para maior fidelidade ao original "qui ma ravi mon bien?"

18 Notemos que "narcisismo" de Emílio no episódio é aquele comandado pelo amor de si. Pois há outra forma de narcisismo, a que tem origem no amor próprio, sentimento que impera nos homens das sociedades modernas e que constitui um dos males do estado presente.

${ }^{19}$ Vargas entende que a lição da propriedade se dá por meio da violência do proprietário - na destruição das favas e em suas palavras - porque é a linguagem que a criança pode compreender. Na infância a criança conhece e representa o mundo a partir da sua posição de fraqueza, do ter menos forças do que precisaria e de tudo ao seu redor sobrepassá-la em força e não cederem a sua vontade; representaria o mundo a partir da idéia de relações entre forças. "O diálogo no decorrer do qual Emílio aprende a ideia de propriedade não é outra coisa que uma relação de forças vivas no qual ele é mais fraco e deve se render - não aos argumentos, mas - à força de seu adversário. O "proprietário" age com pura violência, retoma seu "bem" pela força ao devastar o terreno "usurpado" [...] De onde viria o sentido senão da força, visto que a criança não conhece senão a força, e não conhece senão pela força?" (ROUSSEAU, 1995, p. 52)
} 
pode se dever tanto ao fato de ser uma lição sobre a propriedade, que carrega em si o germe do conflito entre os homens e seus interesses. Quanto pode se dever ao fato de as relações homem-homem serem em si mesmas permeadas por dificuldades, tensões e conflitos. De toda forma, a primeira lição moral que o preceptor, Rousseau, escolhe ensinar a Emílio coloca-o frente à dimensão conflituosa das relações entre os homens, assim como frente ao conflito intrínseco à à própria instituição da propriedade privada. Além disso, podíamos ver na lição, como faz Fortes (1979), que a descoberta do outro implicara a perturbação do idílio amoroso da criança consigo mesma, que, governado pelo amor de si, advinha do prazer de criar e cuidar da própria obra. $\mathrm{O}$ comentador pensa que o processo de educação e aquisição de conhecimento para Rousseau se dá por meio da ativação da piedade natural na criança, isto é, pelo movimento de rompimento de seu mundo fechado, pela saída de si - movimento esse que seria, por sua vez, o contrário daquele do amor de si. ${ }^{20}$

Na sequência da lição Emílio tem a oportunidade, no diálogo com o proprietário, de aprender vários conteúdos acerca da instituição da propriedade, e da ordem social em que ela se inscreve: que antes de plantar num terreno é preciso saber se ele não tem seu dono; que todas as terras no globo já estão ocupadas pela propriedade privadas e seus proprietários; que não restam terras livres para os que, como ele, não tenha terra e possuam desejo de plantar; que a instituição da propriedade requer uma convenção entre os proprietários, a de que ninguém toque na propriedade alheia; que o proprietário não se importa com o fato de Emílio não ter nenhuma terra, e, ao contrário, reafirma seu direito de proprietário; que o proprietário fundamenta seu direito de propriedade no fato de trabalhar a terra, da mesma forma que seu pai, antes dele, lavrava e beneficiava aquela terra; que o direito de propriedade permite ao proprietário o uso exclusivo e excludente de sua terra, desde proibir o seu cultivo por Emílio até impedir que ele a utilize como passagem; que sobre a terra se estabelece a relação da meia, entre o meeiro, que usa a terra, e o proprietário, que recebe pela cessão do usufruto da terra; aprende ainda, podemos dizer, que a propriedade introduz uma relação de desigualdade entre o proprietário, uma posição de força, e o que não tem propriedade, uma posição de fraqueza.

Após aprender os diversos efeitos da instituição da propriedade e ver o proprietário reafirmar enfaticamente seu direito irrestrito àquele terreno, a narrativa faz um desvio, de modo a ensinar Emílio que o conflito com o outro pode ser seguido por acordos e relações de certa harmonia. O preceptor propõe ao proprietário um acordo: ele cederia um cantinho de seu terreno para eles cultivarem e, em troca, eles lhe dariam metade da produção. O proprietário nesse momento se mostra generoso e cede o cantinho sem necessidade do pagamento pelo uso. Ou melhor, cede o cantinho sob uma condição: de eles se manterem nos limites dele e não invadirem outra parte da propriedade. Enfim, com a condição de reconhecerem e respeitarem a propriedade ali estabelecida. Rousseau nos parece pretende ensinar ao aprendiz as duas dimensões das relações homemhomem: antagonismo e a conciliação. Além disso, destacaríamos que a lição sobre a propriedade privada é comandada pelo realismo e pragmatismo - a instituição está consolidada nas socieda-

\footnotetext{
20 "Trata-se de exprimir, com efeito, este movimento de ultrapassamento do "narcisismo" que se acha na base do verdadeiro conhecimento" (FORTES, 1979, p. 83). "Gemer no lugar de Andrômaca e de Príamo é o que fazem o espectador e o ator dramáticos, e, ao mesmo tempo, é o que é necessário produzir por meio da educação” (FORTES, 1979, p. 84).

${ }^{21}$ Ciente de quanto à ideias que pretendia ensinar a Emílio eram contrárias às crenças estabelecidas, Rousseau adverte que o resultado dessa educação estaria longe daquele almejado pelos pais da época. "Alguém de quem só conheço a posição social propôs-me que educasse seu filho. Sem dúvida, foi uma grande honra para mim, mas, longe de se queixar de minha recusa, ele deve louvar minha discrição. Se tivesse aceitado a oferta e errasse no método, seria uma educação falhada; se tivesse sido bem sucedido, seria muito pior, pois seu filho teria renegado seu título e não mais quereria ser príncipe [...] Acredito que, depois de terem lido este livro, poucas pessoas serão tentadas a me fazer essa oferta, e peço a quem poderia sê-lo que não faça a inútil proposta" (ROUSSEAU, 1995, p. 27).
} 
A CENA PEDAGÓGICA | Maria de Fátima Simões Francisco

des do presente e por isso é preciso ensiná-la a Emílio, para que ele, ignorante dessa convenção, não se apodere dos bens alheios e venha a causar mal estar a si e ao outro. Mas, por outro lado, o fato de ter de ensiná-la não obriga a ensiná-la apenas legitimando-a; daí incluir na lição uma série de conteúdos acerca daquela instituição que, somados a outros que virão nas lições futuras, conduzirão a uma visão crítica acerca dessa instituição e da própria sociedade presente como um todo. ${ }^{21}$ Nesse sentido, não haveria inconsistência entre a forte crítica à origem da propriedade privada na história dos povos humanos, que encontramos no Segundo Discurso, e ser essa instituição a primeira noção moral a ser ensinada e incorporada por Emílio. 
A CENA PEDAGÓGICA | Maria de Fátima Simões Francisco

\section{Referências}

CLAPARĖDE, É. J.-J. Rousseau e a concepção funcional da infância. In: A educação funcional. 5. ed. São Paulo: Cia. Editora Nacional, 1958. p. 69-97.

FORTES, L. R. S. Dos jogos de teatro no pensamento pedagógico e político de Rousseau. Discurso, n. 10, p. 79-85, maio 1979.

ROUSSEAU, J.-J. Discurso sobre a origem e os fundamentos da desigualdade entre os homens. São Paulo: Editora Abril, 1973. p. 221-326. (Coleção Os Pensadores).
. Emílio ou da educação. São Paulo: Editora Martins Fontes, 1995.

Émile ou de l'éducation. In: Oeuvres complètes. Paris: Gallimard, 1969a. Tome IV. Lettre à Christophe de Beaumont. In: Tome IV. Oeuvres complètes. Paris: Gallimard, 1969b.

VARGAS, Y. Introduction à l'Émile de Rousseau. Paris: Vrin, 1995. 